\title{
Social Equity Considerations in the Implementation of Caribbean Climate Change Adaptation Policies
}

\author{
Hari B. Dulal ${ }^{1}{ }^{*}$, Kalim U. Shah ${ }^{2}$ and Nilufar Ahmad ${ }^{1}$
}

1 Social Development Department (SDV), The World Bank, 1818 H Street, NW, Washington, DC, 20433, USA; E-Mail: nahmad@worldbank.org

2 The University of Trinidad \& Tobago, Lots \#74-98 O'Meara Industrial Park, Arima, Trinidad, West Indies; E-Mail: kalim.shah@utt.edu.tt

* Author to whom correspondence should be addressed; E-Mail: hdulal@worldbank.org;

Tel.: + 1-202-473-1927; Fax: + 1-202-522-1669

Received: 16 June 2009 / Accepted: 20 July 2009 / Published: 23 July 2009

\begin{abstract}
As the Small Island Developing States of the Caribbean prepare to take climate change adaptation measures, there is a distinct possibility that the most vulnerable groups, especially the poor, women, indigenous, elderly, and children in rural and coastal communities are at risk of being marginalized. It is necessary to take into consideration the adaptation needs of these groups that are likely to be disproportionately affected due to inherent structural and social disparities. In this paper we focus on the need to ensure inclusion and social equity in adaptation planning as climate change issues disproportionately impact health, settlement, and livelihoods of these vulnerable groups. We also focus on climate change potential impacts on tourism, agriculture and fisheries sectors, which are the major economic drivers of these island states. Based on Caribbean region wide observations, we recommend priority areas including increasing community participation, local initiatives and filling critical socio-economic and livelihood data gaps, which policy makers need to focus on and incorporate in their climate change adaptation plans in order to ensure effective and equitable climate change adaptation.
\end{abstract}

Keywords: climate change; adaptation; Caribbean; social equity 


\section{Introduction}

"The degradation of the global environment continues unabated ... and the effects of climate change are being felt across the globe ... But it is the poor ... and developing small island states and elsewhere, who will suffer the most, even though they are the least responsible for global warming."

General Ban Ki-moon, United Nations Secretary General

February 2007

There is now consensus that human-induced climate change is occurring, and is occurring at rates, projected to be unprecedented in recent human history [1,2]. From extinction of species and dislocation of humans due to extreme climate induced events, it is clear that climate change impacts, which are universal, will not only affect natural ecosystems, but will also destabilize socioeconomic systems. Even though every country, irrespective of their developmental status, will be affected, some are at greater risk because of their increased exposure, primarily due to their physical location and weaker adaptive capacity, which is a function of limited resources that these countries allocate towards enhancing the adaptive capacity of their population.

The small island states in Caribbean region will be disproportionately affected by climate change because of their location and greater dependence on sectors such as tourism and agriculture that are highly vulnerable to climate change. The Intergovernmental Panel on Climate Change (IPCC) has categorized the region as a global "hot spot". They also warn that developing countries can expect to experience adverse climatic impacts and that the risks are particularly high for the so-called Small Island Developing States (SIDS). For example, direct impacts are likely to include sea-level rises and storm surges, and indirect impacts will arise as an effect of these. Agricultural losses and ecosystem degradation alone will be enough to jeopardize small island state economies and living standards. The irony, however, is that the island states in the Caribbean are largely victims rather than sources of the problem. The climatic risks they face are disproportionately larger than their contribution to global warming. Caribbean countries are responsible for a very small percentage (only $0.2 \%$ ) of global $\mathrm{CO}_{2}$ emissions [2]. The increasing frequency and intensity of hurricanes over the last two decades have been cited as consequences of global warming and the Caribbean has regularly suffered considerable damage from weather events (2008 with 16 named storms to date was another above average storm season recorded as the $4^{\text {th }}$ most costly hurricane season in Caribbean history). Combined, these storms produced over an estimated US\$11 billion in insured losses, according to the Property Casualty Insurers Association of America (PCI). As of now, at least six Caribbean islands - Haiti, Dominican Republic, Dominica, Jamaica, Martinique and Saint Lucia-are ranked in the top forty countries experiencing extreme weather impacts by the 2009 Global Climate Risk Index. These countries' vulnerability to climate change is partly due to their physical location [3].

Coastal lands represent a proportionally larger share of the total land area. In the Eastern Caribbean, in countries such as St. Lucia, Martinique and Grenada for instance; over 50\% of the population resides within two kilometers of the coast. The projected gradual sea-level rise compounds the threat of climatic induced weather events with the threat of inundation. Due to the concentration of populations 
in the coastal zone, the expected infrastructure damage will be disruptive to economic, social and cultural sustainability.

Besides increased climatic risks resulting from physical location, factors such as weak institutions and crumbling infrastructure have also magnified the vulnerability of the island states in the region. Such macro-economic weaknesses have exacerbated existing vulnerabilities to climatic change.

\section{Social Equity in Climate Change Adaptation}

Climate change is a social equity issue because the poor and disadvantaged groups are the ones that are particularly vulnerable to many of the impacts. Undoubtedly, climate change will impact sociocultural and socio-economic systems, but not all social constituents or communities will be impacted in the same way or to the same degree. The poor are also more vulnerable to extreme climatic events because they tend to reside in hazardous locations with greater exposure to floods, windstorms and landslides, because their quality of housing does not usually conform to codes for disaster-risk reduction, and because of the temporary or "casual" nature of their employment make them usually the first to be laid off when production is disrupted especially in the tourism and agricultural sectors.

In moving forward we must be cognizant of this to ensure social sustainability in the future. Social equity involves fair, just and equitable management of all institutions serving the public directly or by contract, and the fair, just and equitable distribution of public services, and implementation of public policy, and the commitment to promote fairness, justice and equity in the formation of public policy. Operationally, social equity must consider the following four primary areas:

(i) Access by all members of society to due process, equal protection by law and equal rights from existing policies and programs.

(ii) Access to democratically managed goods and services and the right to benefit from such.

(iii) A right to quality and consistency in existing goods and services provided in a democratically managed system.

(iv) Policy outcomes that determine whether policies and programs have the same impact for all groups and individuals served.

All societal groups must benefit from the climate adaptation policies being put forth by local, regional, and national governments. As far as climate change equity is concerned, policies must account for the differential needs of four main, often overlapping vulnerable groups - the poor, the indigenous, women and children. Addressing the adaption needs, which actually may not be very different than livelihood needs, of these groups would help contain further depletion of their resilience to climate change. Besides practical reasons, there are ethical reasons for ensuring that climate change does not accentuate or perpetuate existing social, gender, economic or cultural inequities [4].

\subsection{Social Groups Vulnerable to Climate Change Inequities}

In this study, we refer mainly on the circumstances of the poor, especially women, elderly, children, and marginalized indigenous groups. Often, these groups overlap. They are often excluded and have limited or no access to services and relief materials before, during, and after climatic events. Their livelihood largely depends on coastal resources (e.g., wetlands, alluvial plain agriculture and coastal fisheries). 


\subsection{Potential Impacts of Climate Change on Vulnerable Groups}

Climate change issues facing the Caribbean cannot be framed only as an environmental issue because it has substantial impacts on social, financial, cultural and traditional systems as well. Often, it is only when framed in these latter terms that climate change issues connect to the daily lives of the most vulnerable - poor, women, children, elderly, and marginalized groups.

\section{Increasing Frequency and Intensity of Catastrophic Weather Events}

Many Caribbean countries face an annual threat from hurricanes. Most have extensive, vulnerable, low-lying coastal plains; some (e.g., Barbados, Antigua and Barbuda, St. Kitts, and Bahamas) are heavily dependent on groundwater supplies. A higher incidence of flooding and inundation, beach and coastal land loss, reef damage, salinization of the freshwater lens, and disruption of tourism and infrastructure would create economic and social crises in a number of these islands. Climate change and increases in climate induced extreme events may deplete assets and resources of vulnerable communities. Climate induced changes may therefore become acute for rural and poverty stricken households who have limited assets and access to resources.

Although there still are uncertainties about the extent and mix of effects of climate change, recent literature suggests that the vulnerable groups will be subjected to multiple, simultaneous problems, including food-insecurity, wide-spread loss of employment and production due to abandonment of lowlying areas, high risks of health hazards and large-scale eco-migration, as a consequence of climate change [5,6]. Although social vulnerability is a function of adaptability and there are complexities and certain spatial differences in societal vulnerability to climate change, it is necessary to understand whether the social equity can be maintained in a "climate altered Caribbean context." Future changes in climate pose significant challenges for society, not the least of which is how best to adapt to observed and potential future impacts of these changes. Adaptation must be a dynamic social process driven by collective Caribbean action.

The potentially devastating costs to the Caribbean Small Island States by 2025 if no action is taken to reduce the impacts of climate change has been recently estimated at 14\% of its GDP; increasing to 39\% by $2050,45 \%$ by 2075 and $63 \%$ by 2100 [7]. Even in the past decade, with the increasing incidence of hurricanes, numerous insurance and reinsurance companies withdrew from the market. Those that remained imposed onerous conditions for coverage, including very high deductibles; separate, increased rates for windstorms; and insertion of an "average" clause to eliminate the possibility of underinsurance.

Those communities that are more directly exposed to climatic impacts, more sensitive to change and less able to adapt to climatic changes will necessarily require more consideration as adaptive plans are developed. It is these constituents that policy makers must focus outcomes are to be socially equitable. For this reason, such communities need to be a vital part of the design and implementation of solutions in order to ensure equitable health, well-being and sustainability of all people and the natural environment. 


\section{Increase in Health Related Illness and Disease}

Resource dependent, low income communities are constrained in their capacity to adapt and climate change will increasingly be a key contributor to morbidity, mortality and continued poverty [8]. Direct effects on human health include deaths from extreme weather events, while indirect effects include a range of vector-borne diseases. There is a consensus in association between the frequency and intensity of extreme heat events and climate change.

It is anticipated that an increased frequency or severity of heat waves in the Caribbean would cause an increase in human mortality and illness especially among poor communities without access to cooling aids like air conditioners or refrigeration. Increased frequency of other extreme weather events such as floods, hurricanes, and storm surges would also result in increased deaths, physical injury, infectious diseases, and psychological disorders, especially in disaster-prone countries.

Life-cycle dynamics of the vector-borne parasites will be favored by the anticipated climate change (see Figure 1). Temperature plays a very important role in speeding up the maturation of the malarial parasites inside the mosquitoes [9]. An increase of $5{ }^{\circ} \mathrm{C}$, for example from $20{ }^{\circ} \mathrm{C}\left(68{ }^{\circ} \mathrm{F}\right)$ to $25{ }^{\circ} \mathrm{C}$ $\left(77^{\circ} \mathrm{F}\right.$ ) reduces the Plasmodium falciparum (malarial protozoa) maturity period by half the time (from 26 days to 13 days) [10]. As rate of replication of many infectious agents, vector organisms and nonhuman reservoir species are sensitive to climatic conditions, climate change is expected to increase the incidence of certain vector-borne diseases. Incidences of vector-borne diseases such as malaria, dengue, and cholera, etc., are expected to increases in the coming years (see Figure 1). The possibility of epidemics has also been raised. In eastern African highlands, the increase in the cases of malaria is attributed to local warming $[11,12]$.

Figure 1. Graph showing relationship between temperature rise events and Dengue fever cases for the Eastern Caribbean. Source: [13].

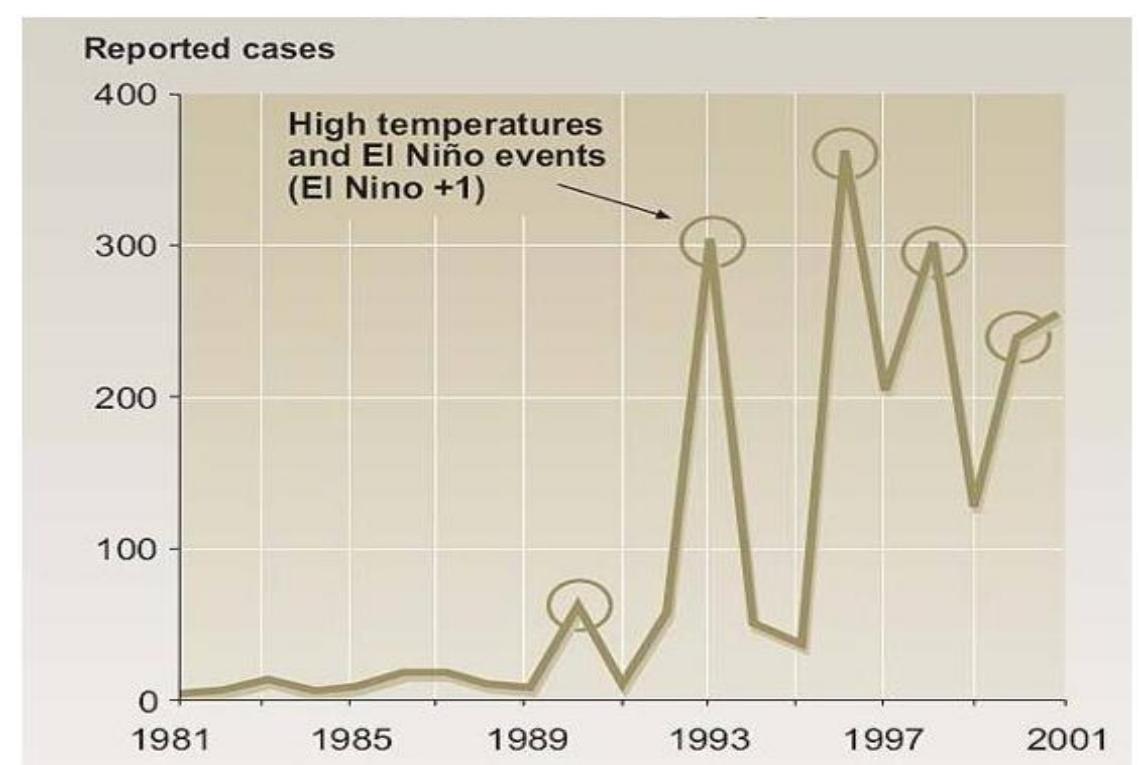


The incidence of non-vector-borne infectious diseases such as cholera, salmonellosis, and other foodand water-related infections may also potentially increase in the Caribbean, especially on islands such as Haiti and Grenada that have minimal public health care infrastructures and in remote, rural parts of larger countries such as Jamaica and Guyana. Another potentially important category of health impact would result from the deterioration in social and economic circumstances that might arise from adverse impacts of climate change on patterns of employment, wealth distribution, population mobility, and limited resettlement prospects [14]. In general, hydrological systems are highly sensitive to climatic changes. With a rise in the occurrence of extreme events, availability of freshwater may be constrained, especially in the tropical countries; and the people there may experience water-related health vulnerability [15].

With climate change becoming more pronounced and climate-induced extreme events more frequent, grassroots action undertaken at the community level will not be enough in reducing vulnerability to current and projected climate change [16].

\section{Intra and Inter Country Eco Migration}

Even though populations have been adapting to the local prevailing climate via behavioral, cultural and technological responses, with the increase in the frequency of climatic events triggered by climate change, communities may be stressed beyond those adaptation limits [17]. The severity of impacts, especially on vulnerable groups in the developing world, will increase because communities are already challenged by various pre-existing socio-economic challenges such as poverty, malnutrition, lack of drinking water and environmental degradations [18].

With the increase in stress, communities may no longer be in a position to sustain their livelihoods. With increase in number of deaths (See Figure 2), vulnerable population may simply move to safer locations. If and when such circumstances arise, often people or household that face climatic risks tend to move to areas with greater security and livelihood options [17]. Agrawal [19] points out that rural communities usually adapt through strategies of mobility, storage, and diversification of livelihood, communal pooling and market exchange. Mobility or eco-migration could prove a significant challenge that public policy in the Caribbean region has yet to address.

The International Committee of the Red Cross estimates that more people are now forced to leave their homes because of environmental disasters than because of war [20]. Some researchers predict, using conservative estimates, that climate change will increase the number of environmental refugees six-fold over the next fifty years [21]. Based on IPCC indications, projected potential environmental refugees by 2050 could be up to 150 million people [21]. However, the concern that climate change impacts will produce waves of refugees is recent [22]. What is easier to forget is that the effects of climate change will also be experienced differently within communities depending on the level of vulnerability people face-factors such as poverty, social exclusion, and dependence on natural resources, poor health and limited access to support services. 
Figure 2. Schematic representation of how an increase in average annual temperature would affect annual total of temperature-related deaths, by shifting distribution of daily temperatures to the right. Source: [17].

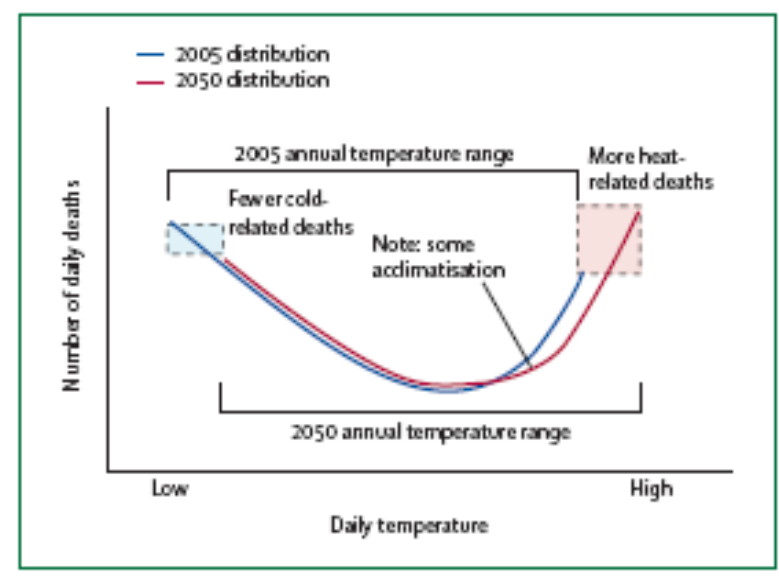

Eco-migration can be in-country, intra-regional, and global. In the face of events brought on by climate change there is the strong possibility that people and entire communities will migrate away from affected areas to safer grounds if possible. The UNHCR identified political instability, economic tensions, ethnic conflict, and environmental degradation as the root causes of refugee flows [24]. Environmental degradation and resource depletion are major contributors to inducing population movement, often filtered through contexts of poverty and inequity [9]. People may sell off their assets and migrate if the natural resource base is degraded to the point where it is insufficient to support the livelihoods of the population [25].

In order to avoid income loss during and after climate induced extreme events, many poor, often males, migrate to larger cities in search of wage labor. Historically, in times of need, there has tended to be migration of workers from smaller islands in the Eastern Caribbean to the larger more industrial countries such as Trinidad, Guyana and Jamaica, These migrations were observed in waves from the 1960 s to the 1990s. Researchers have noted that such migrations have a magnified impact on rural communities, including the breaking up of family units, loss of cultural tradition and increased incidence of social diseases which finds its way back to the rural villages from the cities.

In addition to the physical impacts, the region must concern itself with the impacts on social infrastructure as well. That is, along with the physical damage of climate-induced extreme events such as recurrent flooding and hurricanes, there is also a depletion of "societal resilience" that occurs. Climate resilience is not indefinite. With the increase in the frequency, magnitude, and suddenness of extreme climatic events, depletion of capital assets needed to adapt takes place, as a result of which, adaptation options and strategies become limited. Depletion in resilience because of over-consumption of available assets will leave coastal communities with no options but to move to areas with diverse livelihood options (see Figure 3). It is important to address the issue of resilience depletion because the damage to societal resilience further increases vulnerabilities of the affected population and weakens local institutions' ability to respond and stop the degradation of society's adaptive capacity. Climate proofing of the available social infrastructures and livelihood opportunities is crucial to curb current and future intra and inter-country eco-migration. 
Figure 3. Vulnerability-security continuum. Source: [23].

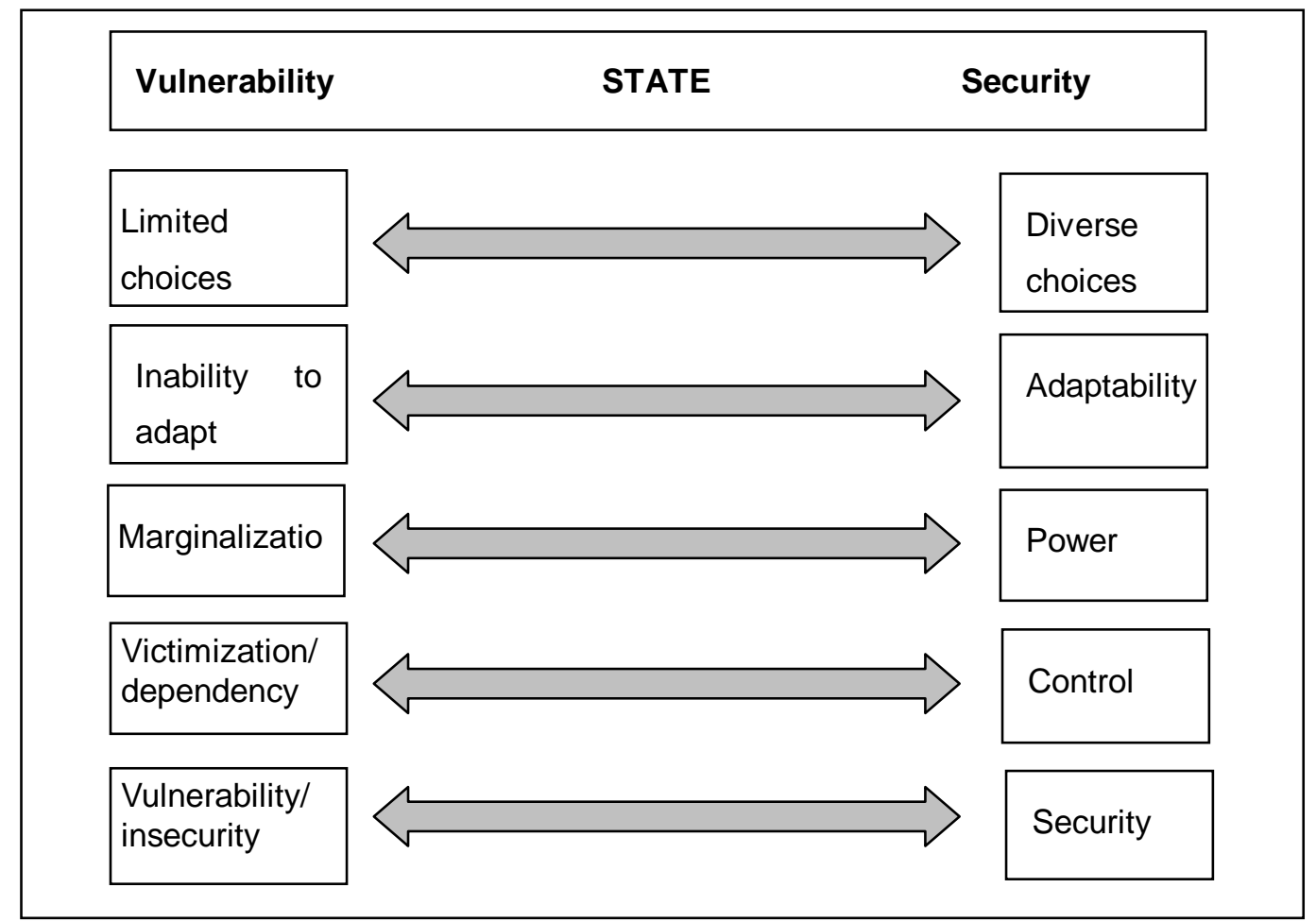

\section{Increased Incidence of Poverty}

In terms of poverty measured by the ability to finance a basic consumption basket of food and nonfood items such as education, housing and transportation, Haiti and Suriname are at the high end of the spectrum of poverty incidence with an estimated $65 \%$ and $63 \%$ respectively of the populations below the poverty line. Clustered in the 30-40\% group are Belize, Dominica, Grenada, Guyana, St. Kitts and Nevis and St. Vincent and the Grenadines. Between $20 \%$ and 29\% are Anguilla, British Virgin Islands, St. Lucia, Trinidad and Tobago and the Turks and Caicos Islands. Barbados had a poverty rate of 14\% in 1997 and Jamaica a poverty rate of approximately 20\% in 2002. In these countries, poverty tends to be more extensive in rural areas than in urban areas, even though urban poverty is more visible and perhaps more socially destabilizing. Rural poverty manifests itself in lack of access to physical and financial resources, production support facilities, and social and physical infrastructure services such as electricity, water, sanitation, and roads and transportation. Urban poverty is revealed in overcrowding, the emergence of squatter settlements, and poor sanitation and waste disposal practices.

The poor, be it in rural or urban areas, have lower economic, social and health resilience and their capacity to adapt to the anticipated adverse situations of climate change is extremely thin. For them, migration is the best intuitive choice. The difficulty in being able to migrate, given the rules and regulations governing migration in cases even within country, but especially across countries, would determine how far they would succeed. People living in a vulnerable zone would face difficulties, given intense competition for limited natural resources and employment and income earning opportunities [26]. Application of appropriate technologies may facilitate enhancement of production and improve employment opportunities, but that would not be enough to offset the anticipated losses and overall degradation of the natural resource base. 
To satisfy the demand of all the community, there would be additional stresses on the resource base and, therefore, a new vicious circle of socioeconomic vulnerability-increased resource exploitation for higher profit-higher degradation of resource base-further resource exploitation causing further resource degradation-productivity and output decline-socioeconomic vulnerability might emerge, leading to unsustainable ecosystems. With increasing physical and socio-economic vulnerability, the people living in an otherwise amicable society may become less sensitive to the needs of others. Competition for resources, employment and services will increase and there will be greater social inequality. Inequality in itself is a major barrier to climate change adaptation. As a result, there may be increased social tensions. Such tensions may not remain confined to particular countries-there may be regional, even international ramifications. If the social disparity is accentuated by adverse effects of climate change, the affected people, unable to find employment, might take recourse to crimes and other anti-social activities, destabilizing the society.

\section{Climate Change and Adaptation by Vulnerable Economic Sectors}

If the Caribbean countries fail to adapt, they are likely to take direct and substantial economic hits to their most important industry sectors such as tourism, which depends on the attractiveness of their natural coastal environments, and agriculture (including fisheries), which are highly climate sensitive sectors. By no incidence, these two sectors are the highest contributors to employment in the majority of these countries and significant losses or economic downturn attendant to inability to adapt to climate change will not increase unemployment but have potentially debilitating social and cultural consequences to communities [27].

The two most significant economic activities in the Caribbean are: tourism and agriculture. These sectors are the main drivers of these small economies and are also likely to be on the frontline of any negative impacts expected from climate change. If these sectors cannot adapt to expected climate change, there will be considerable social upheaval across these small island economies. It is, therefore, imperative that social equity is a vital consideration in adaptive strategies for these two sectors.

\subsection{Economic Losses by Reduction in National GDP}

A recent study focusing on economic losses in the Caribbean derived from three projected effect (hurricane damages, loss of tourism revenue, and infrastructure damage due to sea-level rise) shows that if no mitigative actions are taken the Caribbean's GDP will shrink quite drastically (see Table 1).

Global warming would necessitate more energy for space cooling in warmer zones in the south and, perhaps, less energy for space heating in colder areas. Since energy production and supply in most of the southern countries are less than adequate, the imbalance would be much pronounced under warmer conditions [28]. In order to fund the cost of rehabilitation of and adaptation to damages caused by disasters, people may have to pay more to have access to infrastructure, utilities and services [29]. For instance, cost of protecting road networks in a low-lying area may be recovered by increasing road tax and/or increased cost of transportation in that area. People living in such areas may have to pay more for the same services as a consequence of climate change. Hence, the cost of living is likely to increase in more vulnerable areas, which would in turn decrease the capacity of the affected people to adapt. 
Since the poor and the disadvantaged segments of society have limited means to cope and adapt, their relative vulnerability will be higher compared to rich or non-poor segments of society [30].

Table 1. Caribbean region: low- and high-impact scenarios. Source: [7].

\begin{tabular}{lllll}
\hline Total Caribbean & \multicolumn{4}{l}{ Climate Change Scenarios: \$US Billions } \\
\hline LOW-IMPACT & $\mathbf{2 0 2 5}$ & $\mathbf{2 0 5 0}$ & $\mathbf{2 0 7 5}$ & $\mathbf{2 1 0 0}$ \\
Storms & 1.9 & 2.0 & 2.0 & 2.1 \\
Tourism & 0.4 & 0.8 & 1.2 & 1.6 \\
Infrastructure & 1.5 & 2.9 & 4.4 & 5.9 \\
Total & $\mathbf{\$ 3 . 8}$ & $\mathbf{\$ 5 . 7}$ & $\mathbf{\$ 7 . 7}$ & $\mathbf{\$ 9 . 6}$ \\
& & & & \\
\hline \% of Current GDP & $\mathbf{1 . 8 \%}$ & $\mathbf{2 . 7 \%}$ & $\mathbf{3 . 6 \%}$ & $\mathbf{4 . 5 \%}$ \\
\hline & & & & \\
HIGH-IMPACT & $\mathbf{2 0 2 5}$ & $\mathbf{2 0 5 0}$ & $\mathbf{2 0 7 5}$ & $\mathbf{2 1 0 0}$ \\
Storms & 3.1 & 4.7 & 7.0 & 10.0 \\
Tourism & 2.0 & 4.0 & 6.0 & 8.0 \\
Infrastructure & 9.4 & 18.9 & 28.3 & 37.8 \\
Total & $\mathbf{\$ 1 4 . 5}$ & $\mathbf{\$ 2 7 . 6}$ & $\mathbf{\$ 4 1 . 3}$ & $\mathbf{\$ 5 5 . 8}$ \\
\hline \% of Current GDP & $\mathbf{6 . 8 \%}$ & $\mathbf{1 3 . 0 \%}$ & $\mathbf{1 9 . 5 \%}$ & $\mathbf{2 6 . 3 \%}$ \\
\hline
\end{tabular}

If the cost of adaptation is added to the charges levied for all kinds of social services, then the poorer people will be even more vulnerable. Clearly, climate change will accentuate inequality in a society. Increase in inequality increases the vulnerability of population. Be it within a population, or between different parts of the population, increasing inequality over time, increases collective vulnerability to climate change [31]. The issue of inequity not only relates to a society, it is also an inter-country phenomenon. The world is divided between few rich nations and a large number of poor nations and, within the poor nations, disparity is high with the majority being below poverty levels. Moreover, both inter and intra-country disparities are on the increase.

\subsection{Tourism and Hospitality Sector}

CARICOM, The Caribbean Community, is an organization of 15 Caribbean nations and dependencies. CARICOM's main purposes are to promote economic integration and cooperation among its members, to ensure that the benefits of integration are equitably shared, and to coordinate foreign policy. Tourism is the entirety of the relationships, phenomena and experiences that arise from the traveling and the stay of people in locations or areas other than where they live and work. The industry is heavily dependent on the natural and cultural capital of the island states of the region. Tourism is of utmost policy significance in these SIDS since they have few development alternatives and also because the delicate ecologies and social structures of such destinations are particularly vulnerable to direct and indirect effects of climate change.

The World Tourism Organization estimates that the economic impact of tourism in the Caribbean region is greater than in any other region in the world, since tourism accounts for roughly $17 \%$ of total Caribbean GDP, over $21 \%$ of all Caribbean capital formation, nearly $20 \%$ of total regional exports, and roughly $16 \%$ of total employment, some 2.5 million jobs. In the Bahamas and the smaller islands of the 
Lesser Antilles, tourism's importance is significantly greater than these regional averages might indicate. In St. Lucia, for example, it is estimated that tourism accounts for $56 \%$ of GDP, $60 \%$ of total investment, $65 \%$ of total exports, and $44 \%$ of total employment; in the Bahamas, tourism represents $50 \%$ of GDP; and in Barbados the industry accounted for $47 \%$ of GDP. Even in the least tourism dependent CARICOM nation, Trinidad and Tobago, tourism accounted for $12 \%$ of GDP, $13 \%$ of capital formation and exports, and $8 \%$ of total employment.

Most hotels and tourist facilities are located close to the shore. For example, in Barbados over $90 \%$ of the island's hotels are within proximity of the beach and $70 \%$ of the hotels are within 250 meters of the high water mark; and in Grenada all major hotels are located in the coastal zone, which actually makes up only $3 \%$ of the total land area of the country. Dislocation in the tourism sector would have severe repercussions for the economic, political, and socio-cultural life of these states.

\subsection{Agricultural and Agro-processing Sector}

Although agriculture in some northern areas would perhaps benefit from general warming and $\mathrm{CO}_{2}$ fertilization would have beneficial effect on certain crops, overall global agricultural production might dwindle, depending upon geographic location of impacts. The principal damage will result from heat stress, decreased soil moisture, and an increased incidence of pests and diseases. Since population and, hence, demand for agricultural products, especially for that of food items, would significantly increase, Caribbean food security would face increased challenges under changed climatic conditions. Besides agriculture, other economic activities, such as agro-industries and trade, would also be affected to varying degrees, directly or indirectly. Moreover, the sector specific economic activities are often interconnected and the impacts transmitted by transactions within and between economic sectors [32]. Most of the poor communities of the region lead predominantly traditional agriculture centered livelihoods. They depend on agriculture as owner-operators or agricultural laborers; many are also engaged in agro-industries and petty trading.

Preventing land degradation caused by climate impacts in the Caribbean is a significant issue for rural communities and food security. More than $70 \%$ of the soils in the Caribbean show signs of severe degradation. For example, in the islands of St. Vincent and the Grenadines, at the local level, they currently exhibit classical symptoms of land degradation occasioned by squatting, mono-cropping with poor agricultural techniques, global weather patterns (changes in rainfall distribution, drought and elevated atmospheric temperatures), deforestation and excessive use of agrochemicals. The smaller islands of the Grenadines suffer a similar fate by default.

Communities will need to adapt to changing climate by reducing seawater intrusion and by sourcing new agricultural lands to shift cultivation efforts [5]. Loss or degradation of rangelands would adversely affect livestock production. Competition for land for producing food for human consumption would cause decline in areas for the production of livestock feed. Salinity intrusion would exacerbate the problem even further. Therefore, people depending upon livestock production would face adversities. Climate change would not only cause vulnerability to their agriculture and other economic activities, but will also threaten their employment and health. Using the Erosion-Productivity Impact Calculator (EPIC) and a General Circulation Model (GCM), Mestre-Sanchís and Feijóo-Bello [33] show that climate change causes in loss of jobs in the agricultural sector. 
The process of salinization would reduce available cultivable lands in several islands. As a result, the ongoing process of loss of cultivable land due to other uses (e.g., habitat, roads and urban development) of land caused by increasing population and urbanization will worsen. Many of the coastal productive areas will have to be abandoned. Increased frequency of natural disasters such as floods and cyclonic storm surges would also cause reduction in agricultural production.

These island nations that depend on fisheries will face stresses such as a shift in centers of fish production and change in fisheries species composition and distribution; falling economic returns from fisheries sector; disproportionate suffering among the subsistence and other small scale fisher populations. Climate change may affect revenues from fishing indirectly through stock abundance and stock availability. Both stock abundance and availability affect the catch per unit effort and thus, for constant prices, the revenues from that effort. Fishing costs could be affected by intensification of the seasonal cycle and by any increase in the frequency of storms. Worse weather conditions will increase costs by increasing traveling times to fishing grounds, increasing fuel costs due to rough seas, increasing labor costs due to the working conditions, and increasing maintenance costs due to damage of the vessel, equipment and fishing gear.

\section{Institutional Commitments to Climate Adaptation}

The conceptual right to a "clean and healthy environment" by all society must be considered as a social equity issue. This is alluded to in various MEAs such as The Stockholm Declaration on the Human Environment (1972) Principle 1 which declares that: "Man has the fundamental right to...adequate conditions of life, in an environment of a quality that permits a life of dignity and wellbeing" and the Rio Declaration on Environment and Development (1992) Principle 1 of which states merely that: "Human beings are at the centre of concerns for sustainable development. They are entitled to a healthy and productive life in harmony with nature". Despite this, regional evolution of the climate change challenge has involved a constant re-ordering of socio-economic priorities, of accommodating, adjusting or off-setting mutually restrictive, if not exclusive, public policy objectives. Climate adaptation entitlements have been and will continue to be susceptible to restrictions for the sake of other, socio-economic objectives, such as ensuring continued industrial development.

There are, however, some instances that demonstrate regional commitment to climate adaptation, such as illustrated by the signing of two regionally significant multilateral environmental agreements. These MEAs are the "St George Declaration of Principles for Environmental Sustainability in the OECS"by the Ministers of Environment of Antigua and Barbuda, Anguilla, The Commonwealth of Dominica, Grenada, St. Kitts and Nevis, Saint Lucia and St. Vincent and the Grenadines in 2001; and the Barbados Program of Action concluded at the United Nations Global Conference on the Sustainable Development of Small Island Developing States (1994) by CARICOM members. Acknowledgment of social policy as part and parcel of climate adaptation strategy is highlighted in Principle 8 of the St. George's Declaration, which makes reference to "each Member State to establish appropriate and relevant socially integrated strategies, plans and policies to adapt and respond adequately and in a timely fashion to the causes and impacts of climate change..." and in Principle 11, which goes on to say that the region should "Work together, in collaboration with Civil Society, to promote and facilitate improved national and regional capability for the management of natural resources." Similarly, the 
Barbados Program of Action concluded at the United Nations Global Conference on the Sustainable Development of Small Island Developing States requires States, under Section 34 A to "Develop and improve national databases and the dissemination of information to relevant groups, especially local communities, youth and women, for land-use planning and management, including estimates of carrying capacity, economic and environmental value of land resources..." and also in Section 45 A, which states "Support the involvement of NGOs, women, indigenous people, and other major groups, as well as fishing communities and farmers in conservation ...".

\section{Policy Recommendations}

Equity must play a central role in national and regional climate change adaptation strategies in the Caribbean. SIDS are already under stress from the forces of globalization, population growth, poverty, disease and resource depletion so climate change will interact with these in uncertain and cumulative ways. The island states of the Caribbean hold substantial richness of cultural resources and diversity, making the assurance of social equity a complex topic [34]. By accentuating different groups in differing ways, climate change may exacerbate social disruptions and undermine social sustainability. People suffering from inequity, unemployment and poverty are particularly at risk under climate change. Improving social equity of a particular community under threats of climate change would mean minimizing or eliminating vulnerability and moving towards adaptation. In a two pronged policy approach, countries will need to consider adopting preventive policies and actions such as mitigation; and enhancing resilience of a vulnerable society through effective adaptation. Table 2 identifies some model adaptation response policies based on analysis of social equity conditions across the Caribbean region.

Table 2. Examples of national initiatives that are improving social equity.

\begin{tabular}{llll}
\hline & Policy Action & Impact on social equity & Case example \\
\hline Housing & $\begin{array}{l}\text { Government } \\
\text { commitments to } \\
\text { provide family } \\
\text { housing for } \\
\text { persons classified } \\
\text { as low income }\end{array}$ & $\begin{array}{l}\text { Reduces risk of poor } \\
\text { families squatting in } \\
\text { climate vulnerable areas } \\
\text { groups. }\end{array}$ & $\begin{array}{l}\text { Tax breaks for } \\
\text { residential and } \\
\text { and swamps. }\end{array}$ \\
& & $\begin{array}{l}\text { commercial installation } \\
\text { of solar heaters and } \\
\text { solar panels in }\end{array}$ \\
& & $\begin{array}{l}\text { Barbados; commitment } \\
\text { to utilize low impact } \\
\text { building materials in } \\
\end{array}$ \\
& & government housing \\
& & projects in Dominica, \\
& & Jamaica and other \\
& & \\
& &
\end{tabular}


Table 2. Cont.

\begin{tabular}{llll}
\hline Transportation & $\begin{array}{l}\text { Provision of } \\
\text { national gas } \\
\text { subsidies to } \\
\text { maintain affordable } \\
\text { fuel prices for } \\
\text { commuters. }\end{array}$ & $\begin{array}{l}\text { Allows low income } \\
\text { earners to afford } \\
\text { transportation to } \\
\text { workplace }\end{array}$ & $\begin{array}{l}\text { Provision of government } \\
\text { travel grants for children } \\
\text { of low income homes to } \\
\text { attend schools in islands } \\
\text { including Grenada, St. }\end{array}$ \\
\hline Livelihoods & $\begin{array}{l}\text { Invest in } \\
\text { development of } \\
\text { cleaner industries } \\
\text { and the human } \\
\text { resources to be } \\
\text { employed in these } \\
\text { industries. }\end{array}$ & $\begin{array}{l}\text { Access to specialized } \\
\text { education } \\
\text { opportunities for } \\
\text { new "green jobs" } \\
\text { may not be } \\
\text { accessible to all } \\
\text { communities. }\end{array}$ & $\begin{array}{l}\text { Development of national } \\
\text { education programmes } \\
\text { and institutions. For } \\
\text { example new national } \\
\text { Universities in Trinidad } \\
\text { and Tobago and the }\end{array}$ \\
& & $\begin{array}{l}\text { French Antilles have } \\
\text { been established over the } \\
\text { last five years with heavy } \\
\text { emphasis on "green skills } \\
\text { and environmental }\end{array}$ \\
& & & technology. \\
\hline
\end{tabular}

\subsection{Increase Community Participation Mechanisms in Policy Development}

Participation is a necessary strategy for fostering sustainable development, but effective participatory planning requires methods and skills to accompany the rhetoric. Sustainable development is a process of social and economic advancement that allows for the improvement of the quality of life for all while maintaining and enhancing the natural resources upon which life depends. Because problems of unsustainable resource use often require complex negotiations and trade-offs, processes that include the full participation of stakeholders tend to have the best and most enduring results.

Participation can improve management by: incorporating stakeholder knowledge, skills, perspectives, and opinions; increasing compliance and support through stakeholder involvement in decision-making; providing a forum for identifying and negotiating conflicts; and contributing to local empowerment, especially when the sharing of management responsibility is involved. Unequal rights to property, exclusion from decision-making and difficulties in accessing information and financial services exacerbate vulnerability [25]. For instance, in most Caribbean countries land ownership and property rights legislation dates back to colonial times. Communities in which people live have (or should have) rights relating to the environment in which they live, including the right to be informed and consulted about activities which will have an impact on that environment and the right to ensure that laws and standards established for the protection of the environment are observed [35].

However, perceptions of what participation entails vary widely, and official resistance remains widespread. While it is up to planners and managers to determine what form is most appropriate for any given situation, basic characteristics of effective participatory processes include: the early, active and continual involvement of all stakeholders; the incorporation of the views and opinions of individuals as well as stakeholder groups; provision of information to allow stakeholders to form opinions and make 
decisions; accommodation for the inequities in power among stakeholders; respect for the process and the decisions that are reached.

Participatory planning is only successful when it involves stakeholders in defining the objectives, rules and structures for the process. Other prerequisites include organizational structures that foster stakeholder involvement in management; supportive policy frameworks; and well-informed participants, who are committed to the process, agree with its design, and accept its outcomes. The steps in a participatory process are similar to conventional approaches to planning, the main difference being that stakeholders are involved in most of the steps, using participatory methods. Negotiation among stakeholders is a key element in the identification of options and formulation of decisions. Another difference is that participatory processes are not linear. Action can take place at any stage of the process, as one of its purposes is to provoke change. Participatory processes always begin with the identification and analysis of stakeholders. These two steps aim at providing a basic understanding of the social and institutional context.

\subsection{Strengthen Institutional Capacity}

Institutions play an important role in facilitating adaption because strong, stable, and efficient institutions and good governance enhance the adaptive capacity of the community, society, or the nation. The role of local institutions in adaptation to climate change has been widely recognized. Agrawal [19] broadly identified three main roles in this context: first, structuring impacts and vulnerability; second, defining individual and collective responsibility to adaptation; and third, defining relation with the external agencies. In understanding the role of institutions in adaptation to climate change, there are two discourse gaps: first, absence of theories of adaptation to frame policy debate; and second, absence of comparative studies of role of institutions in adaptation policy intervention.

Adaptation to climate change is highly local. In this context, the role of local institutions is also very important as it impacts the adaptation processes of local community. The most vulnerable communities such as indigenous group, farmers, fishing community, and tribes are tied to their local resources and local social dynamics. They have also developed a variety of adaptation strategies to cope with the climatic variability and change. However, success and limit of adaptation will depend on how the local institution is functioning and responding to the climate change issues.

When compared to a country with good organization and preparedness, a disorganized and unprepared government also means a lower adaptive capacity for a country [36]. Institutional response to the climatic events is important in enhancing adaptive capacity. Sen [37] considers that famines produced by acute food shortages are more a function of unresponsive governance, deprivation and the absence of entitlement than of the intensity of droughts. Adger [38] considers social vulnerability to be the characteristics of the climatic threat, the political economy context in which the institutions attempt to minimize or manage threat and maximize the benefit of society and themselves, and the economic structure and cultural context of adaptation at the individual level.

Adaptive capacity is determined by complex inter-relationships of a number of factors at different scales and is multidimensional in nature. For example: at the national level, in addition to availability of financial resources, adaptive capacity also reflects the degree of institutional capacity and organizational sophistication in targeting those resources effectively to the areas and groups of people that are most 
vulnerable [39]. However, at the household level, adaptive capacity depends on factors such as knowledge base, which enables people to anticipate change and identify new or modified livelihood opportunities, and their access to resources required to maximize their livelihood opportunities [36]. Adaptation needs and priorities may vary from location to another. Lack of access to resources is considered as one of the major barriers towards adaptation. South African farmers cite lack of access to credit as the main barrier to adaptation, where as for Ethiopian farmers, it is access to land, information, and credit [40]. Adaptation, especially anticipatory adaptation would increase the resilience of the vulnerable communities and empower them to safeguard against social inequities. Certain policies must be improved or developed to simultaneously promote socio-economic development and social justice [39]. An overriding focus of the policy regime, in this context, has to be the empowerment of the people for participating in economic, social and political processes in an effective manner, for which ethics and morality must underpin the behavior of the people, particularly of those who are in decisionmaking, program implementation, and leadership positions.

Policies must emphasize improving human skills through education and training; promoting democratic values, institutions, and practices; improving employment opportunities; improving access to resources and social services, particularly of the poor and the disadvantaged; increasing income generation opportunities; and improving health care. There must also be a renewed call for community inclusion and the specification of social equity in policies whereby a commitment to promote fairness, justice, and equity in the formation and operation of communities is stated and made operational. Community policy should include and value everyone and commit to harness national resources to address the threats of climate change.

Adaptation policies must operate hand in hand with mitigation policies, depending on the institutional, financial and other capacities of the particular communities under threat. But SIDS, particularly the most vulnerable ones, may not be in a position to devise appropriate strategies and employ human and other scarce resources. Accentuation of inequities between countries and regions will continue because of the natural progression of globalization and free market development. Promotion of equity therefore is key to sustainability and the Caribbean, understanding this reality and the increasing competition for international funds by other vulnerable regions globally, must seek international cooperative agreements to assist with their climate change adaptation plans. The UN's latest Human Development Report (HDR) estimates that additional adaptation finance needs will amount to US $\$ 86$ billion annually by 2015 . Oxfam puts the price tag at US\$50 billion per year, and the UNFCCC puts it at US\$2,867 billion by 2030. Based on the Oxfam estimate of US\$50 billion and a population of 40 million the Caribbean region will require some US\$430 million annually to meet its adaptation needs.

\subsection{Develop and Measure Indicators of Community Adaptation to Climate Change}

There are several significant gaps in regional and local data regarding vulnerable social groups, without which policymakers will be unable to develop policies and adaptation action plans that fully meet the needs of these constituents. For instance, it will be very instructive if we can learn about the impacts past hurricane catastrophes have had on rural and traditional livelihoods and community structures. Secondly, another area of interest revolves around the important economic and community 
activity of community based tourism. Traditionally rural livelihoods have revolved around some combination of farming, fishing, non-timber forest product harvesting and processing, all of which can lead to resource depletion if not adequately managed. Community-based tourism is the only solution that most Caribbean islands have come up with as alternatives or complements to these activities. Climate change is likely to threaten the tourism attractions on which this depends.

Apart from the examples listed above, there is a need for research on the process of social adaptation in SIDS, including how to develop sustainable and results oriented projects to assist marginalized communities and equitable ways to build policies and institutions. This type of research would facilitate joint learning and consensus building among parties about policy responses in specific contexts for the purpose of developing practical policy options [41] understood and supported by the participating communities.

Adaptation is as much about changing attitudes and behaviors as finding technical solutions. The development of adaptation planning processes and best-practices are context specific. The tools and methods adopted to facilitate adaptation should create opportunities for participation and cater the needs of vulnerable population.

\section{Conclusions}

Caribbean SIDS face significant adaptation challenges which have to be met by governments operating under severe financing constraints and by the large population of poor people themselves. The essential task of adapting societies to climate change is part of a broader transition needed to bring about a more sustainable region. Increasing resources, access to resources and adaptive capacity of more vulnerable communities is a central part of the necessary transition. Thus climate change mitigation and impact reduction need to be integrated into broader socio economic developmental programs aimed at ensuring an equitable future.

Regional governments and policy makers must realize that climate change will not affect everyone equally. The extent to which different communities get affected will be largely dictated by factors such as livelihood context, level of income, level of education, asset holdings, gender, age, and ethnicity. Even within the same community, some may be more vulnerable than others depending upon their level of education, financial status, and physical location. Link equity, economy, and the environment locally, regionally, and globally.

Efforts aimed at poverty reduction are now under way in a broad set of aid and financial institutions. These initiatives need to be expanded and accelerated with greater funding commitments from governments. The development of civil society and the strengthening of local institutions are also necessary since building adaptive capacity must start from the bottom up, from places in which vulnerability resides. This can only occur in a governance system where such views are allowed and heard.

Adaptation will require the dissemination of "best practices" in developing social equity policies and implementing programs from other developing countries and SIDS such as those of the Pacific and elsewhere. The transfer of technologies to developing countries is required. Most knowledge of climate change resides outside of the Caribbean and developing countries need to become more involved. 
Adaptation requires understanding of particular places, particular peoples and particular local cultures [42]. The building of a knowledge system is needed as is sharing of regional best practices.

Caribbean governments must work with urgency to ensure social equity across the board in its current and future social development plans. Many policies currently being implemented can be used to address predicted climate change impacts. These can include current policy moves to provide efficient and effective transportation; supply of housing at affordable rates to the full range of our members of the workforce and diverse communities; fostering business that will create economic, environmental, and social benefits; educating and preparing the workforce and communities to adapt; and support for public health, safety, and social justice in government activities.

\section{Ecutive Summary}

The region must acquire the expertise to craft public policy regarding social equity. Experts must be knowledgeable enough to quickly develop codes to address social equity in regional and national plans for adaptation to climate change. Some of the critical points that experts must then address are the establishment of funding mechanisms focused on areas of need; identification of vulnerable communities by filling the many data gaps in community and rural demographics throughout the islands; implementation of tools such as outreach, public meeting facilitation and visioning to assist the vulnerable.

But climate change cannot be pigeonholed as an "environmental" issue separate from other salient justice issues. Many equity advocates are already using the climate change agenda not only to reduce greenhouse gases but also to address social ills in these various sectors. We see more and more grassroots coalitions forming around climate change, originating and crafting policy ideas in participatory processes, and responsibly laying out the specific impacts of an environmental policy on the socially vulnerable and disadvantaged.

Unfortunately, many policies that purport to address global warming are advanced without strategies targeted to specific socially vulnerable communities. For example, how many government agencies report on the impact of an overall land-use policy to address GHG emissions on a specific low-income community? Equity advocates must now strategically utilize or, even better, fashion climate change policies that benefit, incorporate, and highlight their communities. They can ensure that their communities are not passed over by what is ultimately a powerful government reform movement of both the private and public sectors. Equity advocates must act now to be included in the benefits of climate change programmes and policies.

\section{References and Notes}

1. Adger, W.; Huq, S.; Katrina, B.; Conway, D.; Hulme, M. Adaptation to climate change in the developing world. Prog. Develop. Stud. 2003, 3, 179-195.

2. IPCC Third Assessment Report; Cambridge University Press: Cambridge, UK, 2001.

3. Hales, S.; Kovats, S.; Woodward, A. What El Niño can tell us about human health and global climate change. Global Change Hum. Health 2000, 1, 66-77.

4. Patz, J.A.; Campbell-Lendrum, D.; Holloway, T.; Foley, J. Impact of regional climate change on human health. Nature 2005, 438, 310-317. 
5. Change Adaptation and Human Security. The Royal Norwegian Ministry of Foreign Affairs by the Global Environmental Change and Human Security (GECHS) Project; University of Oslo, Oslo, Norway, 2008.

6. Vergara, W. Adapting to Climate Change: Lessons Learned, Work in Progress, and Proposed Next Steps for the World Bank in Latin America; The World Bank: Washington, DC, USA, 2005.

7. Bueno, R.; Herzfeld, C.; Stanton, E.; Ackerman, F. The Caribbean and Climate Change: The Costs of Inaction; Tufts University: North Grafton, MA, USA, 2008. Available online: http://www.sei-us.org/climate-and-energy/Caribbean-full-Eng-lowres.pdf (accessed on March 12, 2009).

8. O’Brien, K.; Sygna, L.; Leichenko, R.; Adger, W.N.; Barnett, J.; Mitchell, T.; Schipper, L.; Tanner, T.; Vogel, C.; Mortreux, C. Disaster risk reduction, climate change adaptation and human security; GECHS Report 2008:3, University of Oslo: Oslo, Norway, 2008.

9. Lindgren, E. Climate change, tick-borne encephalitis and vaccination needs in Sweden: a prediction model. Ecol. Model. 1998, 110, 55-63.

10. McArthur, R.H. Geographical Ecology: Patterns in the Distribution of Species; Harper and Row: New York, NY, USA, 1972.

11. Lindblade, K.A.; Walker, E.D.; Onapa, A.W.; Katungu, J.; Wilson, M.L. Highland malaria in Uganda: prospective analysis of an epidemic associated with El Niño. Trans. Roy. Soc. Trop. Med. Hyg. 1999, 93, 480-487.

12. Loevinsohn, M.E. Climatic warming and increased malaria incidence in Rwanda. Lancet 1994, 343, 714-718.

13. Amarakoon, D.; Chen, A.; Taylor, M. Climate variability and patterns of dengue in the caribbean. Assessment of Impacts and Adaptation to Climate Change (AIACC) Notes 2003, 2, 8.

14. Luber, G.; McGeehin, M. Climate change and extreme heat events. Amer. J. Prev. Med. 2008, 35, 429-435.

15. Haines, A.; Kovats, R.S.; Campbell-Lendrum, D.; Corvalan, C. Climate change and human health: Impacts, vulnerability and public health. Public Health 2006, 120, 585-596.

16. Ebi, K.L.; Semenza, J. Community-based adaptation to the health impacts of climate change. Amer. J. Prev. Med. 2008, 35, 501-507.

17. McMichael, A.; Woodruff, R.; Hales, S. Climate change and human health: present and future risks. Lancet 2006, 367, 859-869.

18. Dunkelman, I. Climate change: learning from gender analysis and women's experiences of organizing for sustainable development. Gend. Develop. 2002, 10, 21-29.

19. Agrawal, A. The Role of Local Institutions in Adaptation to Climate Change. Social Dimensions of Climate Change; The World Bank: Washington, DC, USA, 2008.

20. World Disaster Report 2001: Focus on Recovery. International Federation of Red Cross and Red Crescent: Geneva, Switzerland, 2001.

21. Myers, N. Environmental refugees in a globally warmed world. Bioscience 1993, 43, 752-761.

22. Myers, N. Environmental Exodus: An Emergent Crisis in the Global Arena; Climate Institute: Washington, DC, USA, 1995. 
23. Africa Environment Outlook: Past, Present, and Future Perspectives; 2002. Available online: http://www.grida.no/aeo/ (accessed on April 4, 2009).

24. The State of the World's Refugees: The Challenge of Protection; United Nations High Commissioner for Refugees (UNHCR): Geneva, Switzerland, 1993.

25. Lambrou, Y.; Laub, R. Gender perspectives on the conventions on biodiversity, climate change and desertification. United Nations FAO: Rome, Italy, 2004.

26. Besley, T.; Burgess, R. Halving global poverty. J. Econ. Perspect. 2003, 17, 3-22.

27. Leslie, K. Challenges posed by climate change to the social livelihoods of people of the Hemisphere. In Presented at the Organization of American States Expert Panel on Climate Change, Washington, DC, USA, 2008.

28. Tanner, L.; Vogel, T.; Mortreux, C. Disaster Risk Reduction, Climate Change Adaptation and Human Security. The Royal Norwegian Ministry of Foreign Affairs by the Global Environmental Change and Human Security (GECHS) Project; University of Oslo, Oslo, Norway, 2008.

29. Haites, E.; Pantin, D.; Attz, M. Assessment of the Economic Impact of Climate Change on CARICOM Countries; Margaree Consultants Inc.: Toronto, ON, Canada, 2002.

30. Laderchi, C.R.; Saith. R.; Stewart, F. "Everyone Agrees We Need Poverty Reduction, But Not What This Means; Does It Matter?" In WIDER Conference on Inequality, Poverty and Human well-being, Helsinki, Finland, May 30-31, 2003.

31. Adger, W.N.; Kelly, P.M. Social vulerability to climate change and the architecture and entitlements. Mitig. Adapt. Strat. Glob. Change 1999, 4, 253-266.

32. Moreno, R.A.; Skea, J. Industry, Energy and Transportation: Impacts and Adaptation; Cambridge University Press: West Nyack, NY, USA, 1996; pp. 365-398.

33. Mestre-Sanchís, F.; Feijóo-Bello, M. Climate change and its marginalizing effect on agriculture. Ecol. Econ. 2009, 68, 896-904.

34. Moore, R. Vulnerability and Adaptation - A Regional Synthesis of the Vulnerability and Adaptation Component of Caribbean National Communications; Caribbean Planning for Adaptation to Global Climate Change: Belize, Honduras, 2002.

35. Toppin-Allahar, C. Environmental Rights; Caribbean Association for Feminist Research: Port-ofSpain, Trinidad, 2004.

36. Vincent, K. Uncertainty in adaptive capacity and importance of scale. Global Environ. Change 2007, 17, 12-24.

37. Sen, A. Poverty and Famines: An Essay on Entitlement and Deprivation; Oxford University Press: London, UK, 1981.

38. Adger, W.N. Social vulnerability to climate change and extremes in coastal Vietnam. World Develop. 1999, 27, 249-269.

39. Kasperson, R.; Kasperson, J. Climate change, vulnerability and social justice; Stockholm Environment Institute: Somerville, MA, USA, 2001.

40. Bryan, E.; Deressa, T.; Gbetibouo, G.; Ringler, C. Adaptation to climate change in Ethiopia and South Africa: options and constraints. Environ. Sci. Policy 2009, 12, 413-426.

41. Belle, N.; Bramwell, B. Climate change and small island tourism: policy maker and industry perspectives in Barbados. J. Travel Res. 2005, 44, 32-41. 
42. Rawlins, S. Stakeholder Engagement and Links to Decision Making: Adaptation to Climate Change / Variability Impacting on Dengue Fever in the Caribbean; University of the West Indies: Mona, Jamaica, 2002.

(C) 2009 by the authors; licensee Molecular Diversity Preservation International, Basel, Switzerland. This article is an open-access article distributed under the terms and conditions of the Creative Commons Attribution license (http://creativecommons.org/licenses/by/3.0/). 